Conclusions: Our present study re-confirms the importance of ACPA, PD $\geqq$ grade 2 articular synovitis and MRI bone oedema, especially the former two, to predict the development of early RA from undifferentiated arthritis patients.

Disclosure of Interest: None declared

DOI: 10.1136/annrheumdis-2018-eular.6534

\section{SAT0089 INITIATING TOFACITINIB IN A TREAT TO TARGET STRATEGY FOR RHEUMATOID ARTHRITIS LEADS TO BLUNTED MULTI-BIOMARKER DISEASE ACTIVITY SCORES AS COMPARED TO ANTI-TUMOUR NECROSIS FACTOR AGENTS}

C. Wiesenhutter ${ }^{1,2} .{ }^{1}$ School of Medicine, University Of Washington, Seattle, ${ }^{2}$ Coeur d'Alene Arthritis Clinic, Coeur d'Alene, USA

Background: The use of a treat-to-target (T2T) strategy for the management of rheumatoid arthritis (RA) leads to better outcomes ${ }^{1}$ but requires the regular use of disease activity measures (DAMs) to make clinical decisions. The optimal DAMs that should be used for this purpose have yet to be determined.

Objectives: To assess the utility of various DAMs for clinical decision making at a rheumatology clinic implementing a T2T strategy, following the initiation of Tofacitinib (tofc) and anti-tumour necrosis factor (ant-TNFs) agents

Methods: Patients at a community based rheumatology clinic (authors) undergo DAM assessments on a routine basis as part of the implementation of a T2T strategy. These assessments include conventional clinical assessments, DAS28CRP, and the CDAI, as well as the ultrasound power Doppler joint count (UPDJC) ${ }^{2}$ and multibiomarker disease activity score (MBDA). Patients undergo regular assessments, and if found to be under inadequate control, changes are made in their clinical regimen, and then the patients are reassessed three to six months later Clinical significance was determined by Paired-samples $T$ tests. Results:

\begin{tabular}{lccccccc}
\hline \multicolumn{7}{c}{ Before } & \multicolumn{7}{c}{ After } \\
\hline & $\mathrm{N}$ & DAS28CRP & $\begin{array}{c}\text { Avg } \\
\pm \text { DD }\end{array}$ & DAS28CRP & $\begin{array}{c}\text { Avg } \\
\pm \text { SD }\end{array}$ & $\begin{array}{c}\% \\
\text { Change }\end{array}$ & Prob \\
Tofacitinib & 39 & 4.90 & \pm 1.00 & 3.78 & \pm 1.20 & $23 \%$ & $\mathrm{p}<0.001$ \\
Anti-TNFs & 40 & 5.07 & \pm 1.08 & 4.09 & \pm 1.01 & $19 \%$ & $\mathrm{p}<0.001$ \\
& & CDAl & & CDAI & & & \\
Tofacitinib & 37 & 29.7 & \pm 11.1 & 17.6 & \pm 12.1 & $41 \%$ & $\mathrm{p}<0.001$ \\
Anti-TNFs & 40 & 29.9 & \pm 11.8 & 21.4 & \pm 12.4 & $28 \%$ & $\mathrm{p}=0.001$ \\
& & UPDJC & & UPDJC & & & \\
Tofacitinib & 37 & 8.9 & \pm 4.0 & 7.0 & \pm 3.9 & $21 \%$ & $\mathrm{p}=0.002$ \\
Anti-TNFs & 38 & 9.3 & \pm 4.5 & 7.3 & \pm 3.1 & $22 \%$ & $\mathrm{p}=0.03$ \\
& & MBDA & & MBDA & & & \\
Tofacitinib & 37 & 48.1 & \pm 12.2 & 44.3 & \pm 10.4 & $7 \%$ & $\mathrm{NCS}$ \\
Anti-TNFs & 38 & 50.0 & \pm 11.0 & 39.3 & \pm 10.9 & $21 \%$ & $\mathrm{p}<0.001$
\end{tabular}

Over the past four years, Thirty nine patients at this clinic were determined to be under inadequate control and were started on tofc. Also, the last forty patients started on anti-TNFs at the clinic were assessed for comparison. The two groups of patients had similar demographics with a combined average duration of clinical disease found to be $>10$ years. Sixty eight $\%$ of these patients were female, and $85 \%$ of patients were rheumatoid factor positive.

Table I shows that all of the DAMs listed resulted in significant clinical responses with the exception that following the institution of tofc, the MBDA did not result in clinically significant improvement. When individual biomarkers from the MBDA were analysed, anti-TNFs therapy lead to significant reduction in six of twelve biomarkers (IL-6, TNF-R1, TNF-R2, MMP-2, SSA and CRP) whereas treatment with tofc lead to significant reduction of two (VCAM and Resisten) and borderline reduction in two (IL-6 and TNF-R1) and a significant increase in one (Leptin).

Conclusions: Several DAMs performed well with the exception of the MBDA after tofc therapy. The MBDA showed a blunted response when compared to other DAMs in the tofc treated group, as well as when compared to patients treated with anti-TNFs. This finding is most likely due to tofc's unique mode of action, as reflected in the relatively small number of biomarkers that decreased following treatment, and the fact that leptin significantly increased.

\section{REFERENCES:}

[1] Smolen J, et al. Ann. Rheum. Dis 2010;69;631-637.

[2] Shin-ya Kawashiri, et al. Rheumatology 2011;50(5):962-965.

Disclosure of Interest: None declared DOI: 10.1136/annrheumdis-2018-eular.3995

\section{SAT0090 \\ EVALUATION OF THE USE OF ULTRASOUND TO MANAGE PATIENTS WITH RHEUMATOID ARTHRITIS OVER TIME: RESULTS FROM THE CORRONA REGISTRY}

D.A. Pappas ${ }^{1}$, K.C. Saunders ${ }^{2}$, C.J. Etzel ${ }^{2}$, D.W. $\mathrm{Hua}^{2}$, K. Deering ${ }^{3}$, P. Zueger ${ }^{4}$, V. Garg ${ }^{4} .{ }^{1}$ Columbia University, New York; ${ }^{2}$ Corrona, LLC, Waltham; ${ }^{3}$ Epi-Q, Inc. Oak Brook, ${ }^{4}$ AbbVie Inc., North Chicago, USA

Background: Musculoskeletal ultrasound (MSUS) imaging in patients with rheumatoid arthritis (RA) can detect synovial inflammation with higher sensitivity compared to physical examination alone. ${ }^{1}$ Not all rheumatologists have adopted the use of MSUS in their daily practice.

Objectives: To compare clinical outcomes in patients whose physicians use MSUS to assess joint inflammation vs those who do not.

Methods: Data from patients $\geq 18$ years old with a confirmed diagnosis of RA who had an index visit in the Corrona RA Registry from 01/01/2012 to 12/31/2015 with $\geq 12$ months of follow-up were stratified into 2 groups: patients whose physicians use MSUS frequently -ie, in $>50 \%$ of their patient encounters - (MSUS group) and patients whose physicians do not use MSUS at all (No-MSUS group). Frequency of MSUS can be recorded and updated by the rheumatologist in the registry questionnaires at every Corrona visit. The index visit was the first visit in which the physician reported the frequency of MSUS use. Outcomes included mean Clinical Disease Activity Index (CDAI) and the proportion of patients in low disease activity (LDA)/remission $(C D A I \leq 10)$ at each time point and were evaluated at index and 1, 2, and 3 years post-index. Comparisons between groups were made using 2-sample $t$-tests for mean CDAl and Chi-square tests fo achievement of LDA/remission.

Results: 21 physicians reported using MSUS frequently compared with 111 who did not use MSUS at all. 5446 of their patients met the criteria for analysis; 1018 (18.7\%) were in the MSUS group and 4428 (81.3\%) were in the No-MSUS group. At the index visit, the MSUS group was younger (mean age 57.7 years vs 59.8 years, $\mathrm{p}<0.01$ ) and had shorter disease duration (mean 8.7 years vs 11.0 years, $\mathrm{p}<0.01)$ compared with the No-MSUS group. At the index visit, the MSUS group had lower mean CDAI (9.7 vs 12.6, $\mathrm{p}<0.01)$ and a greater proportion of patients in LDA/remission $(64.9 \%$ vs $56.8 \%, p<0.01)$ compared with the No-MSUS group; these differences were also present at 1,2 , and 3 years post-index (figure 1).

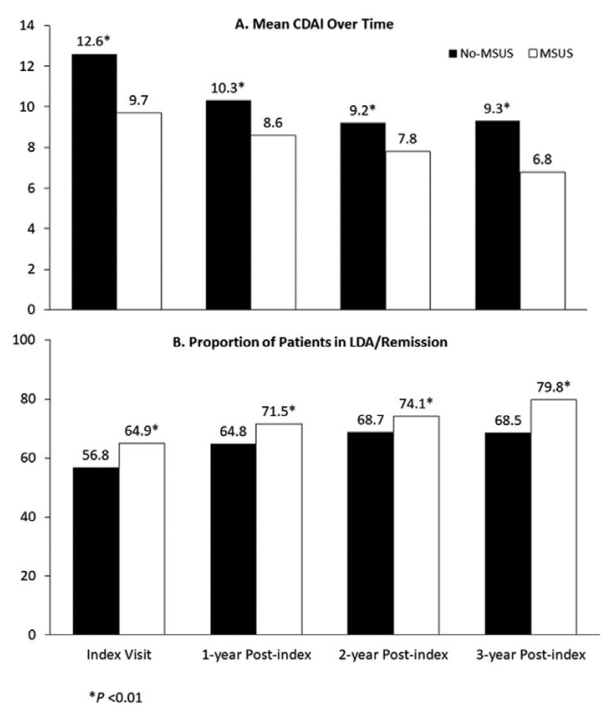

Conclusions: A greater percentage of patients whose physicians use MSUS were in LDA/remission over time. Average disease activity of these patients was lower compared with patients whose physicians did not use MSUS. This pattern was observed at 4 different time points over a 3 year period.

\section{REFERENCE:}

[1] Freeston, et al. Ann Rheum Dis 2010;69:417-9.

Acknowledgements: Corrona has been supported through contracted subscrip tions in the last 2 years by AbbVie, Amgen, Boehringer Ingelheim, Bristol-Myers Squibb, Celgene, Crescendo, Eli Lilly and Company, Genentech, Gilead, GSK, Horizon Pharma USA, Janssen, Merck, Momenta Pharmaceuticals, Novartis, Pfizer Inc, Roche, UCB and Valeant. The design, study conduct, and financial support for the study was provided by AbbVie. AbbVie participated in the interpretation of data, review, and approval of the abstract.

Medical writing services provided by Joann Hettasch of Fishawack Communications and funded by AbbVie. 